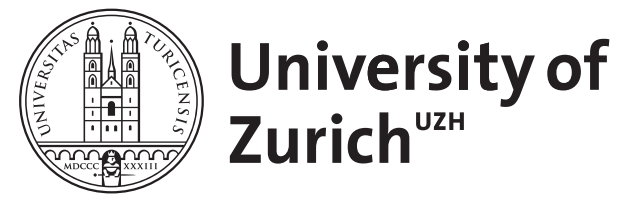
Archive

University of Zurich

University Library

Strickhofstrasse 39

CH-8057 Zurich

www.zora.uzh.ch

Year: 2015

\title{
Speaker-individual rhythmic characteristics in read speech of German-Italian bilinguals
}

\author{
Dellwo, Volker ; Schmid, Stephan
}

Posted at the Zurich Open Repository and Archive, University of Zurich

ZORA URL: https://doi.org/10.5167/uzh-114508

Book Section

Other

Originally published at:

Dellwo, Volker; Schmid, Stephan (2015). Speaker-individual rhythmic characteristics in read speech of German-Italian bilinguals. In: Leemann, Adrian; Kolly, Marie-José; Schmid, Stephan; Dellwo, Volker. Trends in Phonetics and Phonology: Studies from German speaking Europe. Bern: Peter Lang, 349-362. 


\section{Adrian Leemann, Marie-José Kolly, Stephan Schmid \& Volker Dellwo (eds)}

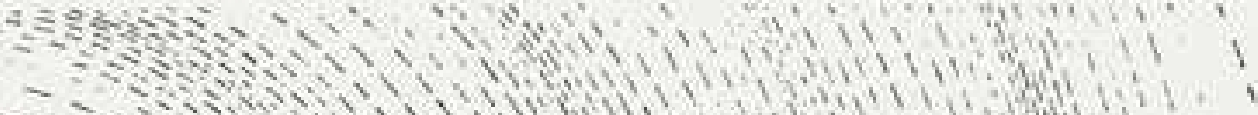

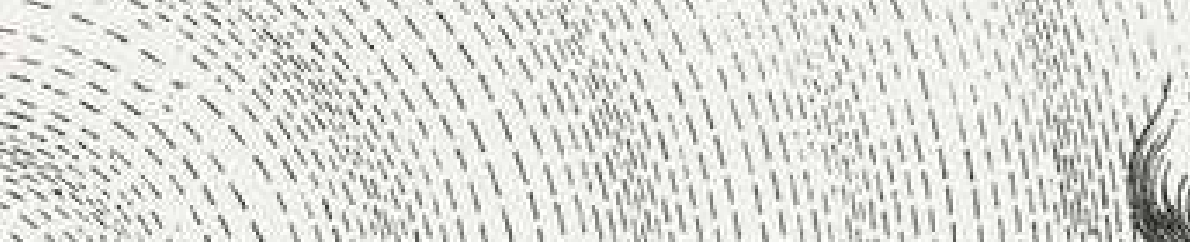

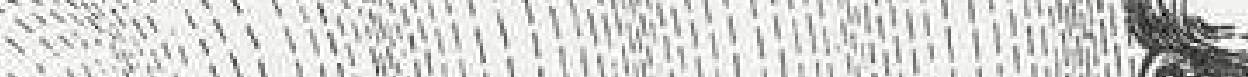
$\because v+11$ ing

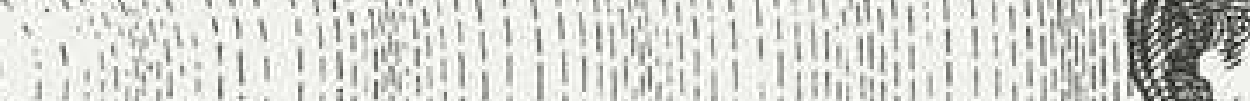
19ton YW,

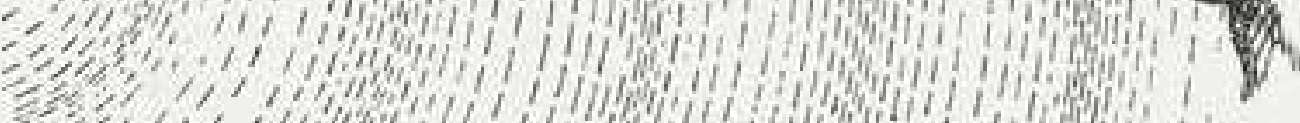
然,

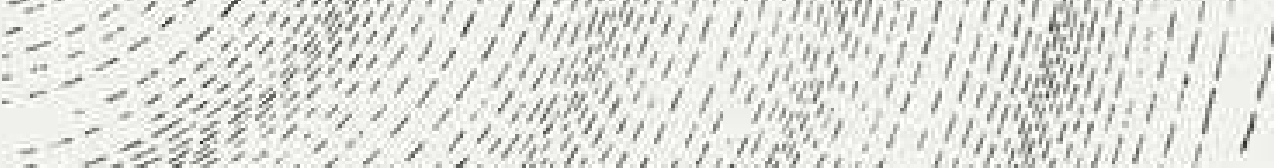

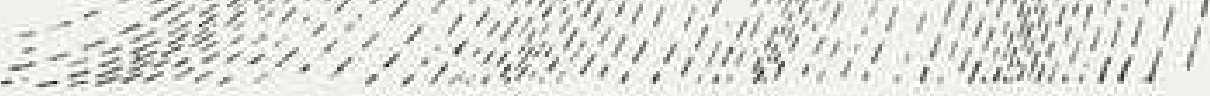

\section{TRENDS IN PHONETICS AND PHONOLOGY}

\section{STUDIES FROM GERMAN-SPEAKING EUROPE}




\section{Adrian Leemann, Marie-José Kolly, Stephan Schmid \& Volker Dellwo (eds)}

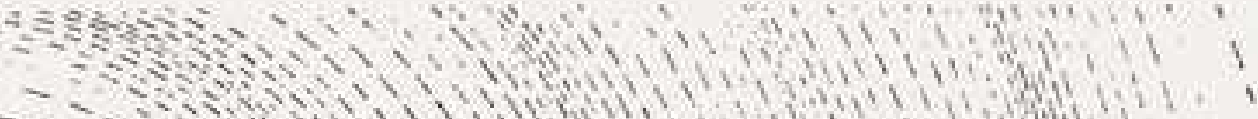

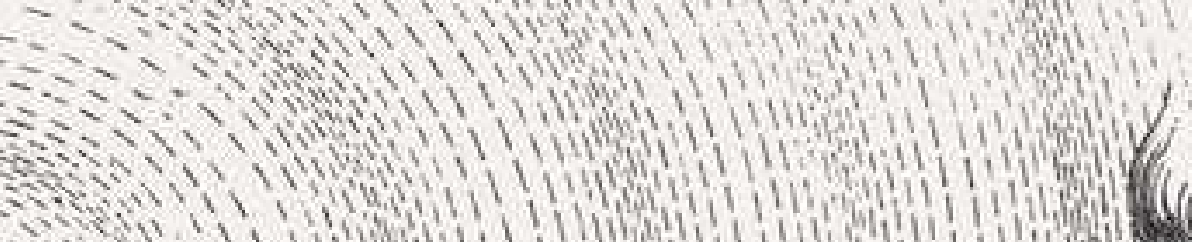

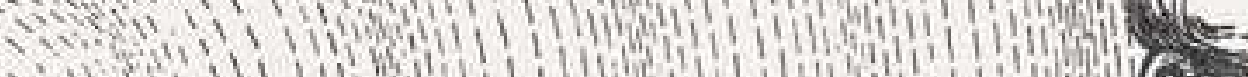
$\because$ Fent

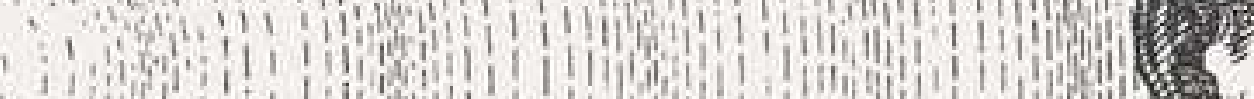
1.9. YNo,

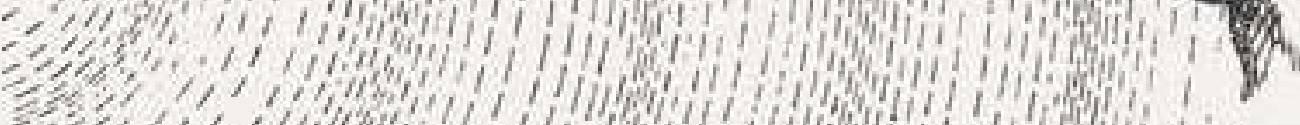

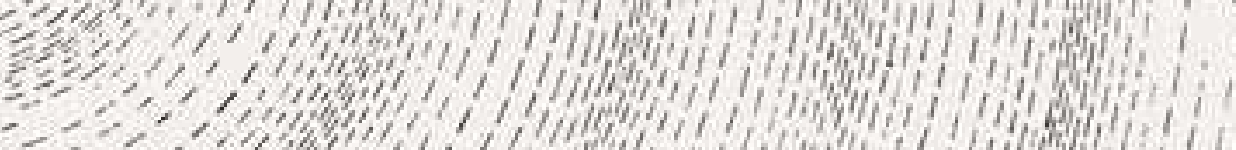

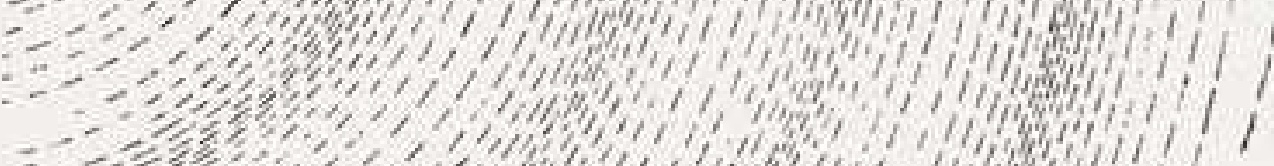

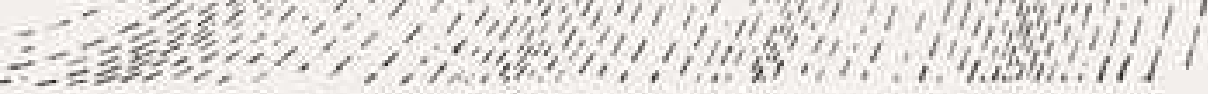

\section{TRENDS IN PHONETICS AND PHONOLOGY}

\section{STUDIES FROM GERMAN-SPEAKING EUROPE}




\section{Table of Contents}

Introduction . . . . . . . . . . . . . . . . . . . . . . 9

\section{Segmentals}

Jürgen Trouvain

On clicks in German .............. . . 21

Ole Schützler

Transforming acoustic vowel data: A comparison of methods, using multi-dimensional scaling . . . . . . . . . . . . . . . . . . 35

Daniel Friedrichs, Dieter Maurer, Heidy Suter and Volker Dellwo

Methodological issues in the acoustic analysis of steady state vowels . . .49

Conceição Cunha, Jonathan Harrington, Sylvia Moosmüller and Julia Brandstätter

The influence of consonantal context on the tense-lax contrast in two standard varieties of German . . . . . . . . . . . . . . . . 65

Julia Brandstätter, Christian H. Kaseß and Sylvia Moosmüller

Quality and quantity in high vowels in Standard Austrian German . . .79

Yshai Kalmanovitch

The role of longterm acquaintances in speech accommodation . . . . . 93

\section{SuPRASEGMENTALS}

Melanie Weirich and Adrian P. Simpson Impact and interaction of accent realization and speaker sex on vowel length in German . . . . . . . . . . . 109 
Nadja Schauffler, Antje Schweitzer, Katrin Schweitzer

and Petra Augurzky

Avoiding melodic clashes in pitch accent production:

A corpus study . . . . . . . . . . . . . . . . . . . . . 125

Petra Augurzky, Arndt Riester and Fabian Tomaschek

Segmental effects on prosody:

Modeling German argument structure . . . . . . . . . . . . . 139

Hansjörg Mixdorff, Ryoko Hayashi and Saori Ushiyama

Identification of word boundaries and accented syllables in German by German and non-German listeners . . . . . . . . . 153

\section{ARtiCULATION IN SPOKEN AND SIGN LANGUAGE}

Tim Bressmann

The poor man's MRI: Reconstruction of pseudo-3D tongue surfaces from multiple coronal ultrasound images . . . . . . . . . . . 171

Felipe Venâncio Barbosa, Janice Gonçalves Temoteo

and Rodrigo Rossi Nogueira Rizzo

What generates Location? Study on the arm and forearm

of lexical items in the Brazilian Sign Language

\section{PERCEPTION}

Fabian Tomaschek, Hubert Truckenbrodt and Ingo Hertrich

Discrimination sensitivities and identification patterns of vowel quality and duration in German /u/ and /o/ instances . . . . . . . . . 197

\section{Christina Otto}

Vertical variation in East Thuringian -

Perception of vowel characteristics of speakers from Zeitz . . . . . 211

Daniel Duran

Perceptual magnets in different neighborhoods . . . . . . . . . . 225 


\section{Phonology}

\section{Mitsuhiro Nakamura}

Conditioning factors in word-final coronal stop deletion in British English: An articulatory-acoustic analysis . . . . . . . . 241

Laurence Voeltzel

Dissimilation in Western Nordic . . . . . . . . . . . . . . . . 255

\section{Crowdsourcing PHONETIC DATA}

Marie-José Kolly and Adrian Leemann

Dialäkt Äpp: Communicating dialectology to the public crowdsourcing dialects from the public . . . . . . . . . . . . . 271

Ingrid Hove, Adrian Leemann, Marie-José Kolly, Volker Dellwo, Jean-Philippe Goldman, Ibrahim Almajai and Daniel Wanitsch Voice Äpp: "My voice - my dialect" . . . . . . . . . . . . . . . 287

\section{SeCOND LANGUAGe SPEECH}

Frank Zimmerer and Jürgen Trouvain

"Das Haus" or "das Aus"? - How French learners

produce word-initial $/ \mathrm{h} /$ in German . . . . . . . . . . . . . . . 303

Milena Insam and Barbara Schuppler

Evaluating the effects of pronunciation training on non-native speech - A case study report . . . . . . . . . . . 317

Mikhail Ordin, Leona Polyanskaya and Petra Wagner

Development of timing patterns in second language acquisition:

A cross-linguistic study . . . . . . . . . . . . . . . . . . . 331

Volker Dellwo and Stephan Schmid

Speaker-individual rhythmic characteristics in read speech

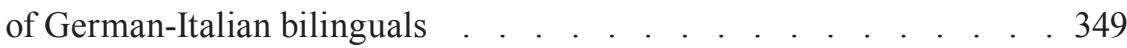




\section{Ursula Ritzau}

The influence of orthographic input on pronunciation: The case of assimilation across word boundaries in second language Danish . . 363

\section{ARTS}

Kostis Dimos, Leopold Dick and Volker Dellwo

Use of speech and prosody in Composed Theatre . . . . . . . . . 379

Dieter Maurer, Heidy Suter, Daniel Friedrichs and Volker Dellwo

Acoustic characteristics of voice in music and straight theatre:

Topics, conceptions, questions . . . . . . . . . . . . . . . . . 393 